\title{
Thermal and Physical Characteristics of Fuel Pellets from Para-Rubber Leaf Litter
}

\author{
Wassachol Wattana ${ }^{1}$ and Ruangnon Kittayaruksakul ${ }^{2}$
}

\begin{abstract}
This study is to propose the thermo-physical properties of fuel pellets made from para-rubber leaf litter. The pararubber leaf litter from local plantation was collected, cleaned, dried and grinded to below $2 \mathrm{~mm}$. The grinded raw material made to solid fuel pellet by a single unit pelletizer under difference condition of compressive pressure. Then pellets were analyzed the combustion behavior by thermogravimetric analysis (TGA). Moreover, the strength and L/D (length to diameter) ratio are also investigated. The results show that, the highest compressive strength was received at 300 psi of compaction pressure. The highest mass loss rate was obtained from $400 \mathrm{psi}$ of compaction pressure at $327^{\circ} \mathrm{C}$, which lower than other compaction pressure conditions. Therefore, having higher compaction pressure provided easier ignition. The compaction pressure of $350 \mathrm{psi}$ is provided highest burnout temperature with also highest amount of residue char for $705^{\circ} \mathrm{C}$ and $9.57 \%$, respectively. It can be concluded from the results of this study that the para-rubber leaf litter is suitable material for pelletization.
\end{abstract}

Keywords - Para-rubber leaves litter, Solid fuel pellet, TG/DTG analysis, Thermal degradation

\section{INTRODUCTION}

$H$ evea brasiliensis, the para-rubber tree, is the major source of natural rubber for the global. There are rapidly expanding of land conversion to rubber plantations in SE Asia around $97 \%$ of the world's natural rubber is produced [1]. Para-rubber plantation is the second economically important crops for Thailand [2]. It produced the most natural rubber in the world, or around 4.4 million tons. There were 920,000 rubber households in Thailand. However, a slowdown in demand (particularly in China) combined with rising stocks due to widespread rubber planting has since led to subsequent price declines of over $70 \%$, leading to the rubber price drop in Thailand [3]. Apart from latex product from para-rubber tree, its tree also produces a large quantity of biomass. It is estimated that a standing tree can produce up to $2.1 \mathrm{~m}^{3}$ of biomass, including the trunk, branches, twigs, and leaves [4]. Fallen leaves that shed from trees become transformed by a natural biochemical processes into a nutrient source for the trees [5]. Para-rubber plantation will shed leaves during the dry season (see Fig.1). The accumulation of para-rubber litter fuel with the hot weather and windy causes a fire spread in the

Wassachol Wattana ${ }^{1}$ is with the King Mongkut Institute's Technology Ladkrabang Prince of Chumphon Campus, Chumphon Province, Chumphon, 86160, Thailand

Ruangnon Kittayaruksakul ${ }^{2}$, was with the King Mongkut Institute's Technology Ladkrabang Prince of Chumphon Campus, Chumphon Province, Chumphon, 86160, Thailand para-rubber plantation every year [2].

All types of lignocellulosic biomass can be used as a feedstock for the production of solid fuel. Lignocellulose is referred to plant matter that composed of cellulose, hemicellulose and lignin. Wood has been the most common type of lignocellulosic biomass utilized as solid fuel or biomass pellets and can be used to generate energy. In addition to wood residue and forestry residues, these biomasses include energy crops and agricultural residues. Since, Thailand is the agricultural country, so there is a plentiful of agricultural residues for produced alternative fuel in the form of fuel pellet.

There are many researches to study the usage of agricultural waste to be a solid fuel or biofuel in the form of pellet. According to Alian Cloutier et al. [6], the influence of the process parameters and raw material characteristics on physical and mechanical properties of wood pellets made from particles of sugar maple trees was to investigated. Pellets were made in a single pelletizer while controlling temperature (75, 100 and $\left.125^{\circ} \mathrm{C}\right)$, moisture content, compression force (1500, 2000 and $2500 \mathrm{~N}$ ) and particle size. They found that the pelletizing process should be performed at a temperature of about $100^{\circ} \mathrm{C}$ at a moisture content of about $11.2 \%$ to maximize density and compression strength of the pellets produced. The six different biomasses: bamboo sawdust, eucalyptus sawdust, corn cob, rubber tree branches, palm fibre and lippia grass were prepared to biomass pellets and to investigated the fuel properties by Mallika Thabuot et al. [7]. The raw materials were milled into small particles less than $5 \mathrm{~mm}$ before pelletization using hydraulic press. Thermal degradation of each biomass was analyzed by TGA (thermogravimetric analysis). They found that the increase in compaction pressure makes the L/D ratio of pellets decrease and the pellet density increase. The higher applied pressure provides the higher tensile strength and less water impermeability of the pellets. The bamboo sawdust was the easiest material to be pressed, and highest pellet density of $1120 \mathrm{~kg} / \mathrm{m}^{3}$. Among those materials, bamboo sawdust has the highest moisture content which effected on low heating value.

The objective of this paper is to investigated the characteristics of fuel pellet made from para-rubber leaf litter. The decomposition characteristic is showed by thermogravimetry analysis. The pellet density, L/D ratio and compressive strength is also evaluated at different compact temperature and pressure. 


\section{METHODS}

\section{A. Materials preparation and pelletizing process}

Para-rubber leaf litters were collected from local plantation (see Fig.1). The leaves were cleaned in water and dried in sunlight for 1 day. Then dried leaves were grinded and sieved to size below $2 \mathrm{~mm}$ and were kept in the seal bag. The pellet from para-rubber leaf litter is produced by single pelletizer consist of die and plug with $10 \mathrm{~mm}$ diameter hole. The plug connected with hydraulic press as show in Fig 2. The grinded leaves around 5 grams was placed into die, then the die was heated to target temperature and plug compressed the raw material inside the die to target pressure and hold for $5 \mathrm{~s}$.

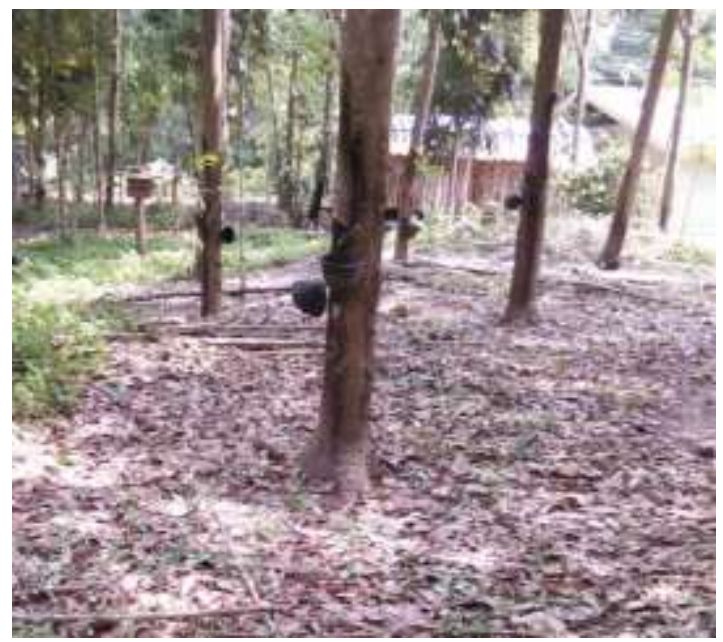

(a)

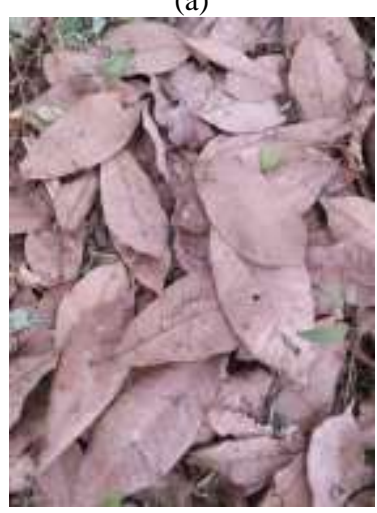

(b)

Fig.1 Para-rubber leaf litter in local plantation (Pathiu district, Chumphon Province, Thailand) (a) para-rubber plantation (b) pararubber leaf litter.

\section{B. Thermal Analysis}

Thermal analysis was performed by using a thermogravimetric analyzer (Pyris 1 TGA, Perkin Elmer). Samples of around $8.5 \mathrm{mg}$ in alumina crucibles were heated from 30 to $900^{\circ} \mathrm{C}$ at a rate of $15{ }^{\circ} \mathrm{C} / \mathrm{min}$ in the presence of nitrogen atmosphere.

\section{Physical Analysis}

Pellet density, L/D ratio and compressive strength were examined as physical characteristics. The sample pellet was placed between flat plates and the top plate was lowered at a constant rate of $1 \mathrm{~mm} / \mathrm{s}$ until its contact with the pellet and failure when pellet cracking. The maximum force at each pellet sample failed $(\mathrm{F})$ was recorded and the compressive strength, $\sigma$, was calculated from (1):

$$
\sigma=\frac{2 F}{\pi D h}
$$

where $\mathrm{D}$ and $\mathrm{h}$ are the diameter and height of the pellet sample, respectively [8].

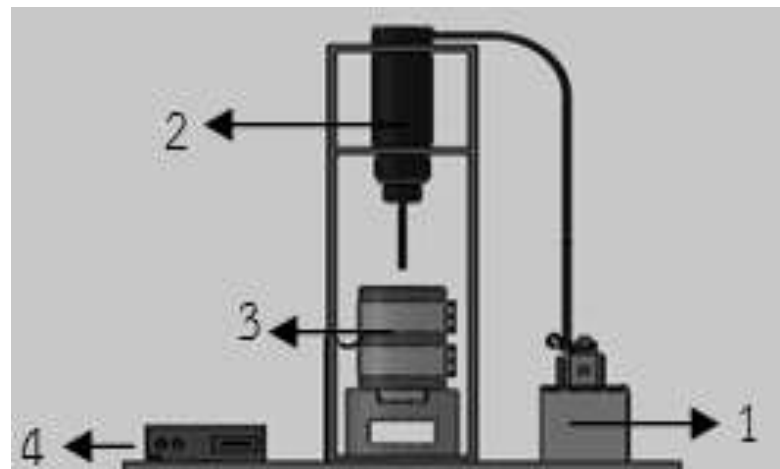

Fig.2 Schematic of single unit pelletizer pellet: (1) hydraulic pump, (2) hydraulic cylinder connected with die (3) mould and heating rope and (4) control box.

\section{RESUlT AND DISCUSSION}

The fuel pellets made from para-rubber leaf litter at different compaction pressures are shown physical appearance in Fig. 3. The effects of pelletizing compaction pressure on fuel pellet made from para-rubber leaf litter were presented in the following results. The some physical characteristics of each fuel pellet at different compaction pressure were shown in Table 1.

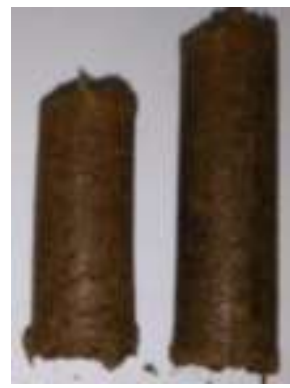

(a)

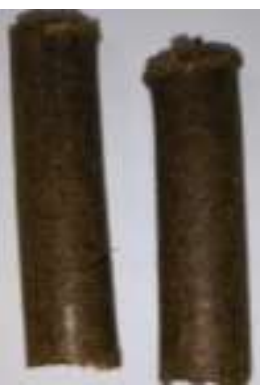

(b)

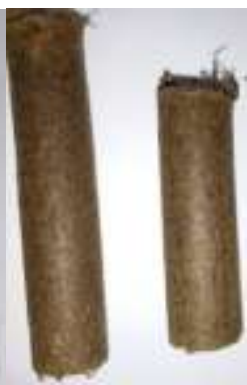

(c)
Fig.3 Para-rubber leaf litter fuel pellet at compaction pressure (a) 300 psi (b) 350 psi and (c) 400 psi.

The L/D ratio (length to diameter) of pellet was increased as the compaction pressure increased, which performed a good degree of compression during pelletization. The highest compressive strength was received at 300 psi of compaction pressure. 
TABLE I

Summarize OF Physical CHARACTERISTICS OF SAMPLE AT DifFERENT PeLletizing Conditions

\begin{tabular}{lll}
\hline \hline $\begin{array}{l}\text { Compaction } \\
\text { Pressure (psi) }\end{array}$ & L/D ratio & $\begin{array}{l}\text { Compressive } \\
\text { Strength }\left(\mathrm{kN} / \mathrm{m}^{2}\right)\end{array}$ \\
\hline 300 & & 288.46 \\
350 & 3.31 & 192.67 \\
400 & 3.92 & 230.16 \\
\hline \hline
\end{tabular}

The thermal degradation behaviors of para-rubber leaf litter pellets at different compaction temperatures are represented in TG and DTG curves and peaks as shown in Fig. 4. From TG curves, the first stage corresponds to moisture and very light volatile matter content in the samples is eliminated at temperature ranging from ambient temperature to $230^{\circ} \mathrm{C}$. ). At this stage there are identical among samples from three compaction pressures. The second stage was indicated by a rapid weight loss beginning at $230^{\circ} \mathrm{C}$ to $350^{\circ} \mathrm{C}$ which occurred from the decomposition of hemicellulose common content of lignocellosic biomass components. The same results can be observed in TG analysis of leaf litter of Mango, Poplar and Ashoka trees as reported by N. Akhtar et al [9]. The third stage was observed from the change of rate of mass loss at temperature around $350^{\circ} \mathrm{C}$ to $700^{\circ} \mathrm{C}, 690^{\circ} \mathrm{C}$ and $560^{\circ} \mathrm{C}$ for compaction pressure 300,350 and 400 psi, respectively. The mass loss at this stage corresponds to the cellulose and lignin decompositions as similar to previous reports which cellulose loss at $350-500^{\circ} \mathrm{C}$ and $>500^{\circ} \mathrm{C}$ for lignin. After that, the rate of mass loss was still constant at the fourth stage, where the carbon content was burnout.

On the DTG curves shown in Fig. 5, the temperatures at which maximum rate of weight loss occurred are indicated by the position of the peaks in the curve. The four distinct peaks were observed which corresponds to four different changes in slope of TG curves. The characteristics of three peaks during combustion process of each compaction pressure were summarized and shown in Table 2. The first peak was the deepest peaks for all condition corresponding to the decomposition of hemicellulose and cellulose which the major component of leaf biomass. The small shoulder can be observed during this process because of the lighter component (hemicellulose) was decomposed and followed by the heavier component (cellulose). The highest mass loss rate was obtained from $400 \mathrm{psi}$ of compaction pressure at $327^{\circ} \mathrm{C}$, which lower than other compaction pressure conditions. Therefore, having higher compaction pressure provided easier ignition. The two remain small peaks were associated with the decomposition of some remaining cellulose and lignin.

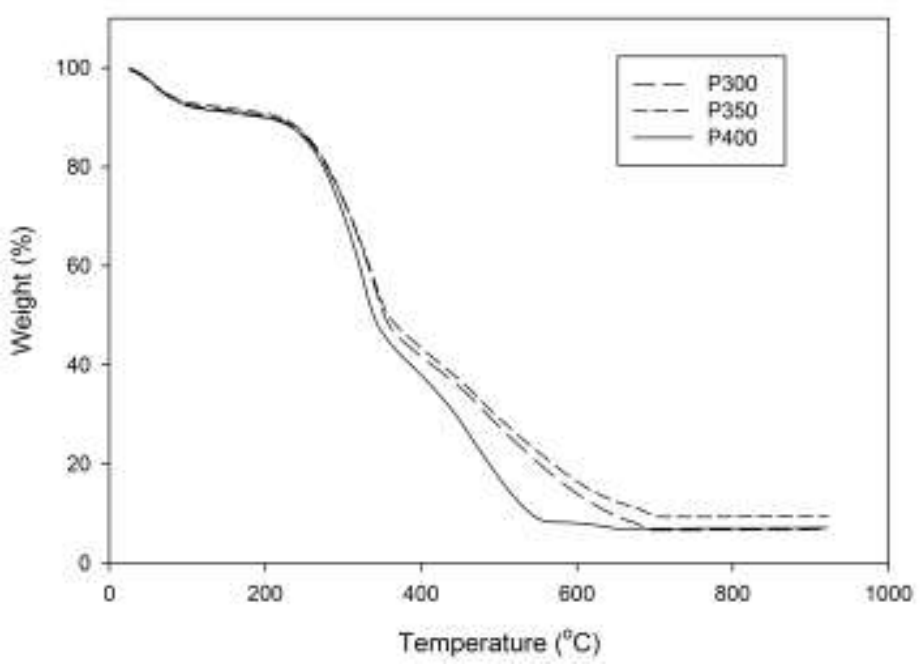

Fig.4 TG analysis of para-rubber leaf litter at different compaction pressure

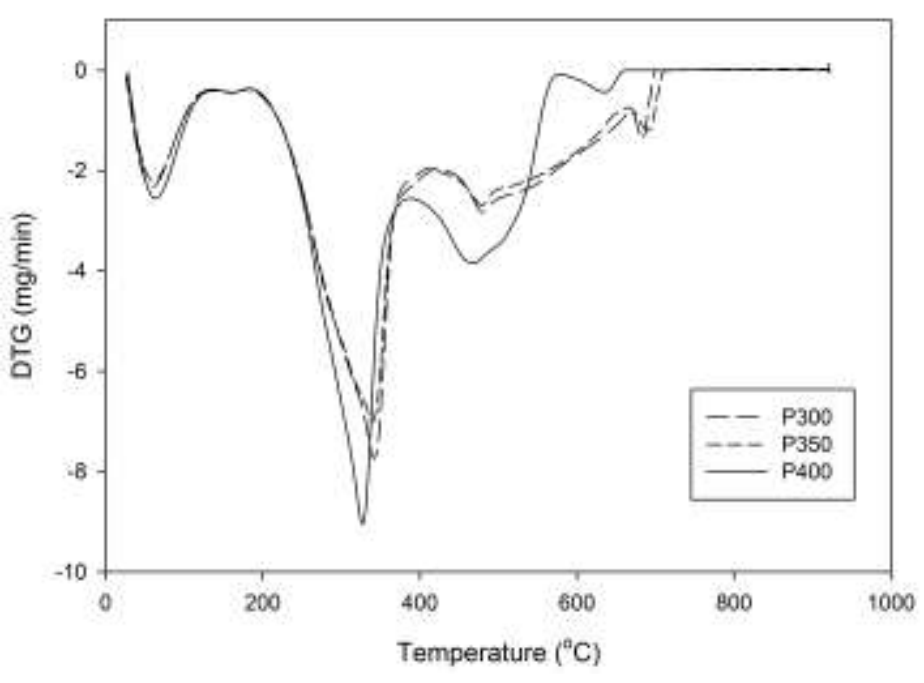

Fig.5 DTG analysis of para-rubber leaf litter at different compaction pressure

The burnout temperature which shown in Table II is the temperature where the rate of weight loss consistently decrease to less than $1 \%$ per min [11]. The higher burnout temperature means the longer combustion period. The compaction pressure of $350 \mathrm{psi}$ is provided highest burnout temperature with also highest amount of residue char for $705^{\circ} \mathrm{C}$ and $9.57 \%$, respectively. The burnout temperature of fuel pellet made from para-rubber leaf litter from this experiment was higher than received from sugarcane bagasse and cotton stalks which reported by S.A. El-Sayed $\left(500-520^{\circ} \mathrm{C}\right)[10]$ but not difference from olive leaves as reported by A. Garcia-Maraver $\left(650^{\circ} \mathrm{C}\right)$ [12]. 
TABLE II

SUMMARIZE OF THERMAL CHARACTERISTICS OF SAMPLE AT EACH PELLETIZING CONDITIONS

\begin{tabular}{llllll}
\hline \hline $\begin{array}{l}\text { Compaction } \\
\begin{array}{l}\text { Pressure } \\
(\mathrm{psi})\end{array}\end{array}$ & $\begin{array}{l}\mathrm{T}_{\mathrm{p} 1} \\
\left({ }^{\mathrm{O}} \mathrm{C}\right) / \mathrm{max} .\end{array}$ & $\begin{array}{l}\mathrm{T}_{\mathrm{p} 2} \\
\left({ }^{\circ} \mathrm{C}\right)\end{array}$ & $\begin{array}{l}\mathrm{T}_{\mathrm{p} 3} \\
\left({ }^{\circ} \mathrm{C}\right)\end{array}$ & $\begin{array}{l}\mathrm{T}_{\mathrm{b}} \\
\left({ }^{\circ} \mathrm{C}\right)\end{array}$ & $\begin{array}{l}\% \\
\text { char }\end{array}$ \\
& $(\mathrm{mg} / \mathrm{min})$ & $\begin{array}{l}\text { max. rate } \\
(\mathrm{mg} / \mathrm{min})\end{array}$ & $\begin{array}{l}\text { max. rate } \\
(\mathrm{mg} / \mathrm{min})\end{array}$ & & \\
\hline 300 & $342 /-7.73$ & $480 /-2.82$ & $684 /-1.38$ & 693 & 6.78 \\
350 & $340 /-6.99$ & $479 /-2.69$ & $691 /-1.18$ & 705 & 9.57 \\
400 & $327 /-9.04$ & $468 /-3.84$ & $635 /-0.43$ & 652 & 7.12 \\
\hline \hline
\end{tabular}

\section{CONCLUSIONS}

Fuel pellet from para-rubber leaf litter has been analyzed both physical and thermal properties. The grinded leaf litter was compressed into pellets with three compaction pressure 300,350 and $400 \mathrm{psi}$ at $110^{\circ} \mathrm{C}$. The highest mass loss rate was obtained from $400 \mathrm{psi}$ of compaction pressure at $327^{\circ} \mathrm{C}$. The compaction pressure of $350 \mathrm{psi}$ is provided highest burnout temperature with also highest amount of residue char for $705^{\circ} \mathrm{C}$ and $9.57 \%$, respectively. It can be concluded from the results of this study that the para-rubber leaf litter is suitable material for pelletization. However, further more study is needed in order to clarify the more properties and quality of fuel pellet.

\section{ACKNOWLEDGMENT}

This study has been undertaken with the financial support from King Monkut's Institute of Technology Ladkrabang, Prince of Chumphon Campus, Chumphon Province.

\section{REFERENCES}

[1] J. Fox and J.C. Castella, "Expansion of rubber (Hevea brasiliensis) in Mainland Southeast Asia: what are the prospects for smallholders?," The Journal of Peasant Studies, vol.40, issue 1, pp. 155-170, 2013. http://dx.doi.org/10.1080/03066150.2012.750605

[2] P. Wongchai and W. Tachajapong, "Effects of Moisture Content in Para Rubber Leaf Litter on Critical Mass Flux and Piloted Ignition Time," Energy Procedia, vol.79, pp. 448-452, 2015. http://dx.doi.org/10.1016/j.egypro.2015.11.517

[3] J. Prachaya, "Rubber Economist Quarterly Report. First Quarter 2015," The Rubber Economist Ltd., London and Bangkok. 2015.

[4] J. Ratnasingam, G. Ramasamy, L.T. Wai, A.L. Senin, and N. Muttiah, "The prospects of rubberwood biomass energy production in Malaysia," Bioresources, vol.10, issue 2, pp. 2526-2548, 2015. http://dx.doi.org/10.15376/biores.10.2.2526-2548

[5] L. Pnakovic and L. Dzurenda, "Combustion characteristics of fallen fall leaves from ornamental trees in city and forest parks," Bioresources, vol.10, issue 3, pp. 5563-5572, 2015.

[6] Q. N. Nguyen, A. Cloutier, A. Achim, andT. Stevanovic, "Effect of process parameters and raw material characteristics on physical and mechanical properties of wood pellets made from sugar maple particles," Biomass and Bioenergy, vol. 80, pp. 338-349, September 2015.

http://dx.doi.org/10.1016/j.biombioe.2015.06.010

[7] T. Unpinit, T. Poblarp, N. Sailoon, P. Wongwicha, and M. Thabuot, "Fuel Properties of Bio-Pellets Produced from Selected Materials under Various Compacting Pressure," Energy Procedia, vol. 79, pp. 657-662, November 2015. http://dx.doi.org/10.1016/j.egypro.2015.11.551

[8] A. Bazargan, S. L. Rough, and G. McKay, "Compaction of palm kernel shell biochars for application as solid fuel," Biomass and Bioenerg, vol. 70, pp. 489-497, November 2014.

http://dx.doi.org/10.1016/j.biombioe.2014.08.015
[9] N. Akhtar, D. Goyal, and A. Goyal, "Physico-chemical characteristics of leaf litter biomass to delineate the chemistries involved in biofuel production," Journal of the Taiwan Institute of Chemical Engineers, vol. 62, pp. 239-246, 2016. http://dx.doi.org/10.1016/j.jtice.2016.02.011

[10] S.A. El-Sayed and M.E. Mostafa, "Pyrolysis characteristics and kinetic parameters determination of biomass fuel powders by differential thermal gravimetric analysis(TGA/DTG)," Energy Conversion and Management, vol. 85, pp. 165-172, 2014. http://dx.doi.org/10.1016/j.enconman.2014.05.068

[11] Sa. A. El-Sayed and M. E. Mostafa, "Kinetic Parameters Determination of Biomass Pyrolysis Fuels Using TGA and DTA Techniques," Waste Biomass Valor, vol.6, pp. 401-415, 2015. http://dx.doi.org/10.1007/s12649-015-9354-7

[12] A. Garcia-Maraver, D. Salvachua, M.J. Martinez, L.F. Diaz, and M. Zamorano, "Analysis of the relation between the cellulose, hemicellulose and lignin content and the thermal behavior of residual biomass from olive trees," Waste Management, vol. 33, pp. 2245-2249, 2013.

http://dx.doi.org/10.1016/j.wasman.2013.07.010 